\title{
Rethinking explicit utterance content
}

\begin{abstract}
This paper challenges the view that interpreting an assertoric utterance of a declarative sentence requires representing the explicit content of the utterance, where this is understood to be a level of representation that is development of the linguistically encoded meaning of the utterance. Such a form, often referred to as an 'explicature' or 'impliciture', is assumed to be an output of pragmatic processing by both Sperber \& Wilson's Relevance Theory and in Recanati's two-system model. The paper considers a number of reasons why such a level might be posited, and concludes that none of these is sufficient to require the view that utterance interpretation processes aim at identifying a level of explicit content that is arrived at by augmenting and/or adjusting the encoded meaning of the sentence uttered. Rather, the paper argues, the distinction drawn by Jary (2013) between material and behavioural implicatures better explains certain phenomena highlighted by putative tests for explicit utterance content, and provides a principled basis for the distinction between two levels of pragmatic processing.
\end{abstract}

\section{Introduction}

There is a widely held view that interpreting an assertoric utterance involves adjusting and/or augmenting the meaning of the linguistic form uttered so that a representation which has the truth conditions of the assertion can be entertained by the interpreter. This view is motivated by the concern that the encoded, or 'conventional', meaning of an utterance generally underdetermines what is asserted by the speaker. Consequently, it is assumed that hearers must engage in processes of adjustment and enrichment of linguistic meaning in order to identify the truth-conditional content of the utterance.

The idea is often expressed in terms of sentences uttered being less than fully explicit representations of the content of the assertion. This lack of explicitness, it is then argued, must be remedied at some level, in order that the hearer grasp the content of the utterance. The underlying assumption is that a given interpretation can be expressed more or less explicitly, so that (1), (2) and (3) could all be expressions, of varying degrees of explicitness, of the same interpretation/message.

(1) She came

(2) Mary came

(3) Mary came to the party 
The idea defended by most theorists in this area is that because utterances are rarely, if ever, fully explicit, pragmatics must be called upon in order to arrive at a fully explicit representation of the utterance's truth-conditional content. This fully explicit representation is called an 'impliciture' by Bach $(1994,2001)$. For Bach, it is required to complement Grice's notions of what is said and what is implicated: what is said is determined by the linguistic meaning of the utterance, after reference assignment and disambiguation, what is implicated is that which is implied by the saying of the former. The impliciture, he says, is implicit in what is said, not implied by it. Bach, however, departs from Grice in that Grice wanted what is said to count as the content of what is asserted by the speaker of a declarative sentence. Bach, by contrast, sees what is said as non-illocutionary, in Austin's (1962/1975) sense; the truth-conditional content of the assertion, in Bach's framework, is the impliciture of the utterance.

Relevance Theorists (Carston, 2002; Sperber and Wilson, 1986/1995; Wilson and Sperber, 2012) agree with Bach that the asserted content of an utterance of a declarative sentence is not Grice's what is said, and also that what is asserted by a speaker is a development of the linguistic meaning of the utterance, though they prefer the term 'explicature' for the result of this development. Relevance Theorists differ from Bach, however, in what they do with Grice's notion of what is said: Bach strips this of illocutionary force, but nevertheless retains it; Relevance Theorists, by contrast, reject the notion outright, claiming that it has no role to play in a theory of utterance interpretation. In this they are at odds with Bach, who argues that a non-assertoric version the Gricean notion of what is said is required "to account for the hearer's access to the linguistic content of an utterance" (Bach, 1994: 158).

I will not here discuss the merits of these two positions. Rather, I want to consider whether it is necessary to posit that interpreting an (assertoric) utterance necessitates the hearer identifying and representing the explicit content of the utterance. It is not clear that Bach holds that representing his implicature is a necessary part of utterance interpretation: his concern is primarily with taxonomising aspects of utterance content (both speaker-meant and not). However, Relevance Theorists, along with Recanati $(2002,2004)$, certainly posit the representation of the utterance's explicit content as an output of utterance processing. As will be seen below, this is the claim that I aim to challenge in this paper.

\section{Explicit utterance content}

The explicit content of an utterance, it is generally agreed by authors writing on this topic, is arrived at by augmenting and adjusting the linguistic meaning of the utterance in accordance with the 
speaker's intentions. A range of types of developments have been posited, with a distinction drawn between those that are linguistically mandated and those that are not. Linguistically mandated developments are classed as 'saturation'. The best-known example is the resolution of reference for indexicals, though, as Carston (2009) points out, there are many more cases than the classic Kaplanian indexicals to be considered:

(4) Paracetamol is better.

[than what?]

(5) It's the same.

[as what?]

(6) He is too young.

[for what?]

(7) It's hot enough.

[to what?]

(8) I like Sally's portrait.

[portrait in what relation to Sally?]

Non-linguistically mandated developments of linguistically encoded meaning are known as cases of 'free enrichment'. These are cases where a proposition would be expressed by the saturated linguistically encoded meaning of the utterance, but the resulting proposition is not a fully explicit expression of what is asserted by the speaker. Consequently, further enrichment is needed. This has in turn been divided into two broad types: the supplying of so-called 'unarticulated constituents' and adjustments of lexically encoded meaning. Examples of the former would be the enrichment of the a-example to the b-example in the following (both from Carston, 2009).

(9) a. I've had a shower

b. I've had a shower today

(10)a. Mary gave John a pen and he wrote down her address.

b. Mary gave John a pen and then he wrote down her address with the pen that Mary gave him.

The second type of free enrichment, lexical adjustment, involves the modulation of the encoded meaning of a lexical item. Some more examples form Carston (2009):

(11)Boris is a man.

(12)Buying a house is easy if you've got money.

(13)Let's get rid of the empty bottles. 
(14)This policy will bankrupt the farmers.

In (11), the speaker is not claiming merely that Boris is a human male, but that he is particular type of human male, perhaps an ideal type or a typical type, depending on the speaker's intentions; in (12) a certain quantity of money is clearly intended; in (13) the bottles are unlikely to be, strictly speaking, empty; in (14) the farmers may not be technically bankrupt, and the speaker would not be taken to be claiming that they will be. Cases such as (11) to (14) are often viewed as cases of lexical adjustment, with the lexically encoded meaning of a word argued to undergo modification as part of the comprehension process to form an ad hoc concept (Carston, 2002; Sperber and Wilson, 1998; Wilson, 2003; Wilson and Carston, 2007).

I neither deny nor dispute the observations made about these cases. Rather, I want to separate the compelling observations from the claims that they are employed to support. Key is the claim that, because the linguistic forms themselves are not fully explicit expressions of the assertoric content of the utterance, hearers must, as part of the process of interpreting the utterance, develop its encoded/conventional meaning into a fully explicit representation of its assertoric content. In other words, I want to challenge the claim that interpreting an utterance requires representing its explicit content, where this is derived by making adjustments and augmentations to its linguistically encoded/conventional meaning.

First, though, I need to consider the distinction between utterances and their interpretations. The distinction is important to current concerns because it is generally assumed, albeit tacitly in most cases, that the two have features in common. This, I will argue, is an unnecessary assumption and one which is liable to prejudice the debate.

\section{Utterances and interpretations}

The idea that utterances linguistically underdetermine the content of what the speaker asserts-and the articulation of this idea in terms of explicitness-presupposes that the stuff in which interpretations consist is also to be found in the linguistic forms whose utterance provokes these interpretations. Interpretations are generally conceived of as semantic contents: truth-conditional objects of some sort. On the views under consideration here, the linguistic form of an utterance is held to consist partly of the same stuff, for without this assumption, the notion of adjusting and/or augmenting that form makes little sense. Even if it is held that full explicitness is an ideal that may never be achieved, the assumption that linguistic forms can be placed on a scale of explicitness in relation to a given interpretation presupposes that linguistic forms and the interpretations to which their utterance gives rise are made, to some degree, of the same stuff. 
Given this assumption, the idea that interpreting an assertoric utterance involves 'developing' what is encoded by the linguistic form of the utterance is difficult to contest. However, it is an assumption, not an observation. In order, therefore, not to prejudice the debate, I will employ a different conception of the relationship between an utterance and its interpretation, one which does not assume that the two share features such that adjusting and augmenting the former will give rise to the latter.

On the conception that I propose to employ, utterances are events that consist in the production of tokens of linguistic types for communicative purposes, and interpretations are constraints on behaviour, verbal or otherwise, that result from those utterances. In the case of an assertion, the constraints can be thought of as inferential and practical commitments and entitlements undertaken by the speaker, and also by the hearer if he assents to the assertion (a view drawn from Brandom, 1994). On this view, given that 'that' has the same reference on each occasion, an utterance of (15) results in commitment to (16) (such that the speaker of (15) must also assent to an assertion of (16)), and in a lack of entitlement to (17) (such that the speaker of (15) can neither assert nor assent to an assertion of (17)).

(15)That is a rose.

(16)That is a flower.

(17)That is a daffodil.

This conception of the relationship between an utterance and its interpretation has the advantage of being based on observation rather than assumption. The sorts of commitments and entitlements it treats as constituting interpretations are facts, not theoretical entities: when required to defend the claim that (15) entails (16), we point to the fact that one cannot both assert (15) and deny (16). In other words, we point to the constraints on behaviour that follow from the assertion of (15). Furthermore, this conception does not pre-judge the issue of whether linguistic forms and their interpretation have something 'contentful' in common, and hence removes the prejudice in favour of the view that interpreting an utterance involves adjusting or augmenting the content of the linguistic form uttered. On this view, interpretations are restrictions on behaviour, not semantic objects of any sort. Of course, these restrictions relate in part to which further speech acts can or cannot be performed, but these speech acts are manifestations of interpretations, rather than interpretations themselves. We might characterise the interpretation in terms of the subsequent speech acts that are and are not ruled out by that assertion, but this does not entail that the interpretation itself is a set of language-like forms which share semantic content with the utterance. 
On this view, the observations that motivate the claim that interpreting an utterance involves developing the linguistically encoded content of the utterance can be recast. Take for example an utterance of (18), which on this occasion of utterance we will say results in commitment to (19):

(18)John's car is fast.

(19)The car that John is driving is fast.

The theorist observes that there are other commitments that could, under different circumstances, have resulted from the utterance of (18), such as (20). In other words, we have a linguistic form that is compatible with more than one interpretation but whose utterance on a particular occasion nevertheless results in only one.

(20)The car that John designed is fast.

The theories under consideration in this paper take this observation to constitute grounds for the assumption that interpreting (18) on this occasion involves developing its linguistic meaning so that it has the content of (19). But one need not say this. It is also open to us to say that the interpretation of (18) on that occasion of utterance resulted in commitment to (19). Conceived of thus, (19) is an assertion that the speaker is committed to making, or assenting to, by virtue of his utterance (18). In other words, rather than an interpretation of (18), (19) can be seen as a manifestation of an assertoric commitment undertaken by the utterance of (18). This manifestation comes with its own set of commitments, but the set of commitments that a tokening of (19) might result in is narrower than that of (18), and a tokening (19) is not liable to lead to commitment to (20), under most circumstances. For this reason, we might call (19) more explicit than (18).

This way of looking at things is compatible with the linguistic adjustment/enrichment view: one may argue that the reason the speaker of (18) is committed to (19) is that interpreting the former involves adjusting and augmenting its content until it becomes the latter. However, presenting the data as I have suggested above shows that it does not require that view: there is a more parsimonious alternative. Consequently, independent motivation is needed for the linguistic adjustment/enrichment view. In the next section, I will consider motivations that might be put forward, and argue that none gives sufficient grounds for positing the adjustment/enrichment of linguistically encoded meaning.

\section{Justifying the linguistic adjustment/enrichment view}

There are three broad reasons that might be put forward to defend the view that interpreting an utterance involves adjusting and augmenting linguistically encoded content. The first is that we have 
intuitions about what a speaker commits herself to on a particular occasion of utterance, and that these intuitions distinguish between commitments that are closely related to the linguistic meaning of the utterance and those that are not. Furthermore, the former type of commitment has a special status in human affairs, as evidenced by the lying/misleading distinction and the importance of what is asserted versus what is implied in legal disputes. The second reason relates to linguistic phenomena such as embedding under logical connectives. The case would be that the connectives appear to take in their scope more than the encoded meaning of the sentence uttered, thereby indicating that what they take in their scope is actually an adjusted and/or augmented version of what the linguistic form provides. The last is that models of utterance interpretation, if they are to be models of rational behaviour, require a step in which warrant for the implicatures of an utterance is derived. This warrant, the argument goes, is the explicit content of the utterance, which is underdetermined by the linguistically encoded content of the utterance, and hence must be derived as part of the interpretation procedure. I will consider each of these reasons in the following sections.

\subsection{Intuitions about the assertoric content of utterances}

The first case for the claim that interpreting an utterance involves adjusting and augmenting lexically encoded content relies on the fact that we have intuitions about what a speaker asserts and how this differs from what she otherwise conveys by virtue of her utterance. Consider the following example from Carston (2008c).

(21)X: How is Mary feeling after her first year at university?

Y: She didn't get enough units and can't continue.

In this example, $\mathrm{Y}$ communicates the following two assumptions:

(22)Mary did not pass enough university course units to qualify for admission to second year study and, as a result, Mary cannot continue with university study.

(23)Mary is not feeling very happy.

The intuition we have is that the commitment undertaken by $Y$ to $(22)$ is very different to that undertaken to (23): the latter is implied, and might be denied without contradiction (the speaker might go on to say 'but she's not bothered as she's just inherited a fortune and will never need to work'). By contrast, the speaker has undertaken a much firmer commitment to (22), and, intuitively, that speaker could not avoid this commitment without withdrawing her utterance. The fact that (22) shares features with Y's utterance in (21) leads to the assumption that the former is derived by 
adjusting and augmenting the latter, while (23) is derived by some other means. This view is reinforced by the fact that a reconstruction of an inference from (22) to (23) is available (given the assumption that not being able to continue one's university course is a cause of sadness), whereas there is no straightforward inference from Y's utterance in (21) to (22).

But while this makes it plausible that interpreting Y's utterance in (21) requires augmenting and adjusting the linguistically encoded meaning of that utterance until (22) is derived, the view sketched earlier in this paper provides an alternative, according to which (22) is a manifestation of the interpretation of $Y^{\prime}$ 's utterance, rather than the outcome of that process. According to this view, (22) is an alternative utterance that $Y$ is committed to making or assenting to, one that is more restrictive (in terms of the commitments an utterance of its linguistic form can give rise to) than $Y^{\prime} S$ actual utterance. The intuition that $Y$ is committed to (22) can be analysed as the intuition that (22), had it been uttered in the same situation, would result in broadly the same set of commitments as her actual utterance. The difference between the two utterances is that the linguistic form of $Y^{\prime} \mathrm{s}$ actual utterance could be used in a wider range of situations, and is thus compatible with a wider set of interpretations, than (22). An utterance of (23), by contrast, would not lead to the same set of commitments as Y's utterance in (21), even though it is also a manifestation of the interpretation of her utterance.

We can therefore distinguish between manifestations of an interpretation that can substitute for the original utterance and those that cannot, this distinction reflecting the intuitive distinction in commitment type that we observe between what is asserted and what is implied. Consequently, the view that utterance interpretation involves augmenting and adjusting the linguistically encoded meaning of the utterance is not required in order to explain the distinction between what is asserted and what is otherwise communicated by an utterance. Intuitions about what is asserted by an utterance can be explained, rather, by considering which manifestations of the interpretation of an utterance can substitute for the original utterance and result in that same interpretation, i.e. in the same set of commitments being undertaken. Of course, this is somewhat of an idealisation: for any given utterance, it is unlikely that there will be another form whose utterance would have resulted in exactly the same set of commitments (see Hinzen, 2015). But we are concerned here with intuitions that result from reflecting on utterances, not facts about the interpretation of utterances.

\subsection{The scope of logical connectives}

The development of notions such as impliciture and explicature arose out of a concern that the distinction Grice had drawn between what is said and what is implicated by an utterance was 
inadequate. Doubts about Grice's distinction were first raised by noting that the logical connectives appear to be sensitive to elements of utterance content that Grice saw as implicatures (Cohen, 1971). This is at odds with Grice's view that the truth conditional content of the utterance is fully determined by what is said.

Because of their sensitivity to the truth-conditional content of an utterance, falling under the scope of a logical connective such as 'if' or 'or' has been applied as a test for whether an aspect of communicated meaning is part of the explicit content of the utterance, this being dubbed 'the scope test' by Recanati (for discussion, see Carston, 2002: 191-197; 1989)

Consider one of Cohen's examples:

(24)The old king has died of a heart attack and a republic has been declared.

(25)A republic has been declared and the old king has died of a heart attack.

(26)If the old king has died of a heart attack and a republic has been declared, then Tom will be quite content; but if a republic has been declared and the old king has died of a heart attack, then Tom will not be at all content.

Such data pose a problem for Grice because, if the encoded meaning of 'and' just is the truthfunctional logical ' $\&$ ', then (24) and (25) should be truth-conditionally equivalent. But, embedding under 'if' can result in a difference in truth conditions, as (26) shows: were the two 'if' clauses identical in content, then (26) would be contradictory. It is important to note, however, that Cohen's arguments against Grice do not in themselves make the case for a notion of explicit utterance content, understood as a level of representation derived from the linguistically encoded meaning of the utterance. Rather, what they show is that one cannot simultaneously hold that the conventional meaning of a connective such as 'and' is no more than its truth-functional meaning, that the truth conditions of a sentence are determined solely by its conventional meaning (after disambiguation and reference assignment), and that natural language logical connectives such as 'if' take the truth-conditional content of a sentence (or its utterance) in their scope.

That said, assuming (a) a distinction between explicitly and implicitly conveyed utterance content (i.e. between explicature and implicature, in Relevance Theory terms), and (b) the identification of explicit content with the truth-conditional content of an assertoric utterance, embedding under logical connectives would seem a reliable means of distinguishing explicitly and implicitly conveyed utterance content. Furthermore, this might reasonably be thought to be a result of natural-language logical connectives taking an enriched version of a sentence, such as (27) or (28), in its scope.

(27)The old king has died of a heart attack and as a result a republic has been declared. 
(28)A republic has been declared and as a result the old king has died of a heart attack.

However, thinking of the interpretations in terms of commitments undertaken and their manifestation in subsequent utterances, as advocated earlier in this paper, allows an alternative view. One can say, following Brandom (1994), that the role of conditional sentences is to specify (or 'make explicit') the commitments undertaken by an assertion. On this view, 'if' takes in its scope a sentence and the subsequent clause specifies commitments associated with an assertion of that sentence. What (26) then shows is that the commitments associated with (24) and (25) are distinct, and, as these commitments are manifestations of the interpretations of (24) and (25), that the interpretations of (24) and (25) are distinct. The conditional, on this view, specifies a consequence of asserting the sentence embedded under 'if', but all that gets embedded is the sentence itself, not an enriched and/or augmented version of it. To judge a conditional sentence true, on this view, is to accept that commitment to the consequent follows from asserting the antecedent.

This analysis raises the question of what the scope test does distinguish between, if not between explicit and implicated utterance content. The answer, I will now argue, is between content conveyed by the linguistic meaning of the utterance and that conveyed by the speaker's verbal behaviour. This distinction is drawn in Jary (2013), where I call the former 'material implicatures' and the latter 'behavioural implicatures'. I will briefly outline this distinction before showing that it partitions the data along the same lines as the scope test.

The difference between material and behavioural implicatures rests on the fact that a distinction can be drawn between those implications of an utterance that are conveyed by considering the speaker's verbal behaviour, and those that are implied by the sentence uttered. Rational reconstruction is used as a diagnostic: if the implication can be derived in a reasonable inference that takes the sentence uttered as the initial premise, then it is a material implicature; if by contrast, a rational reconstruction of the derivation of the alleged implicature must start with a description of the speaker's verbal behaviour, then it is a behavioural implicature. Consider first Grice's famous philosophy job reference example, in which an utterance of (29) implicates (30) (Grice, 1989).

(29)Mr X's command of English is excellent, and his attendance at tutorials has been regular.

(30)Mr. X is no good at philosophy.

Then contrast (30) with Grice's out-of-petrol example: B's utterance in (31) is said to implicate that the garage in question is probably open and selling petrol

(31)A: I am out of petrol 
In the latter case, there is an inference from the explicit content of the utterance to the implicatures that can be reconstructed as follows:

i. There is a garage round the corner

ii. Garages are usually open on weekdays during normal working hours

iii. Now is a weekday during normal working hours

iv. Garages normally sell petrol

v. Therefore, the garage round the corner is probably open and selling petrol

No such reconstruction is possible in the philosophy-job example, however. In that case, any reconstruction must move from a premise about the speaker's verbal behaviour to the implicature, as we see below:

i. She has stated that Mr. X's command of English is excellent, and his attendance at tutorials has been regular.

ii. She has said nothing about Mr. X's merits as a philosopher.

iii. She knows that information about Mr. X's merits as a philosopher is what would be most relevant to my concerns.

iv. She is not opting out of the Cooperative Principle, for she has bothered to write.

v. Therefore there must be something she intends to communicate that she is unwilling to write down.

vi. This must be that $\mathrm{Mr}$. $\mathrm{X}$ is a poor philosopher.

We have, then, a distinction between implicatures that are, in terms of rational reconstruction, derivable from (Gricean) what is said and those that require premises that relate to the speaker's verbal behaviour, and her mental states. In the first type of case, the sentence uttered provides the input to the reconstruction of the inference to implicated content. In the second case, what she says itself has little to do with what she implicates: the fact that she has said this, and her reasons for doing so, i.e. facts about her behaviour, are key. Behavioural implicatures are on a par with nonlinguistic means of communication, such as winks and ostensive deliberate frowns. In such cases, a form of behaviour is overtly produced in order to invite explanation by identifying the intention 
behind it, and once this intention has been identified, the message has been conveyed. Cases of material implicature, such as the out-of-petrol case, are different in that it is the linguistic content of the utterance that warrants the implicatures. ${ }^{1}$ To be sure, facts about the utterance (such as the speaker's goals and intentions) justify supplying the appropriate auxiliary premises, but these facts are not required to ensure that an inference from the linguistic meaning of the utterance to its implicatures is a reasonable one.

Aspects of utterance meaning that are opposed to those that are claimed to fall in the scope of the logical operators are in fact instances of behavioural implicature. For example, consider, (32), which conveys (33).

(32)Mary lives somewhere in the south of France.

(33)The speaker does not know where in the south of France Mary lives.

This example is given by Carston (2002: 194) as a case of pragmatically conveyed meaning that falls outside the scope of a connective. Citing Green (1998), she notes that if (33) were part of the truthconditional content of (32), then (34) should be tautologous, which it is not:

(34)If Mary lives somewhere in the south of France, then I do not know where.

But (33) is clearly a behavioural implicature: it follows from the fact that the speaker has uttered (32) rather than a more informative sentence. There is no reasonable inference from (32) to (33) that does not require premises concerning the speaker's verbal behaviour and her mental states. This is in contrast to cases such as (24): that a change in the system of government might result from the death of a monarch relies on knowledge about likely patterns of constitutional change, rather than on facts about a speaker's behaviour and the mental states underlying this. ${ }^{2}$

\footnotetext{
${ }^{1}$ The Gricean notion of meaning-nn and its Relevance Theory successor (ostensive-inferential communication) ignore this distinction by taking non-linguistic acts of meaning conveyance as paradigmatic.

${ }^{2}$ Another example discussed by Carston (from Grice, 1989) might appear problematic for my analysis. In the dialogue (i), Bob's response conveys (ii):

(i) a. Ann: Does Bill have a girlfriend these days?

b. Bob: He flies to New York every weekend.

(ii) Bill probably has a girlfriend who lives in New York.

The inference from (i)b to (ii) is a reasonable one and consequently (ii) should count as a material implicature. However, it is cited by Carston as a case in which a pragmatically conveyed part of the total utterance content does not contribute towards the truth conditions of the utterance. Part of her case is that, in the conditional (iii), "the consequent (that Bill must spend a lot on travel) depends just on the proposition that Bill flies to New York every weekend and not on him having a girlfriend there" (Carston, 2002).

(iii) If Bill flies to New York every weekend he must spend a lot on travel.

However, it is a fact that flying costs the same regardless of one's reason for doing so: it is thus no surprise that the consequent in (iii) does not depend on Bill having a girlfriend in New York. If we use a different
} 
The scope test, therefore, is best seen as distinguishing materially from behaviourally conveyed utterance content. The conditional is a means of specifying the consequences of an assertion by making explicit its consequences. On this view, there is no need to claim that 'if' takes in its scope any more than the linguistic meaning of the embedded sentence. To be sure, that sentence needs to be related to a particular situation of utterance, but this is inherent in the claim that the conditional specifies the consequences of asserting that sentence: assertions are events that take place under particular circumstances.

\subsection{A level of representation required by models of utterance interpretation?}

The third reason one might claim that interpreting an utterance involves adjusting and augmenting linguistically encoded meaning in order to entertain a representation of the explicit content of the utterance is that models of utterance interpretation, if they are to be models of rational behaviour, require a step in which warrant for the implicatures of an utterance is derived.

The idea that the interpretations of utterances should be a rational process can be traced, of course, to Grice (1989). Implicatures, on his account, must be calculable: for a communicated proposition P to be labelled an implicature of an utterance, it must be possible to show how $\mathrm{P}$ can be derived from what is said and the fact that it has been uttered, given certain assumptions about the norms governing linguistic communication (which Grice sought to capture with his Co-operative Principle and Maxims of Conversation). In other words, it must be possible to provide a rational reconstruction of the interpretation. Of course, Grice never claimed that such inferences were always explicitly thought through as part of every act of utterance interpretation, acknowledging rather that there will be many short cuts in the actual psychological processes.

Those seeking to develop cognitive models of utterance interpretation have nevertheless tried to respect Grice's rationality requirement, even though they have not treated the actual process of interpretation as one of explicit reasoning from what is said to what is implicated. Consequently, they have sought to build into their models something like a 'rationality check', i.e. a step which ensures that the interpretation arrived at is warranted by the speaker's verbal behaviour. In Sperber \& Wilson's Relevance Theory (Sperber and Wilson, 1986/1995; Wilson and Sperber, 2002, 2012) this takes the form of the identification of a proposition which is both a development of the linguistically encoded meaning of the utterance (i.e. an explicature) and a warrant for the implicatures of the

conditional sentence to apply the scope test, by contrast, then the consequent does depend on Bill having a romantic interest in New York:

(iv) If Bill flies to New York every weekend he must be very much in love. 
utterance. In this section, I outline the Relevance Theory model, and argue that the step of explicature identification is redundant.

Sperber \& Wilson argue that the linguistically encoded meaning of an utterance acts not as a premise in reasoning about utterance content, but as a stimulus that initiates a process that results in the explicature and implicatures of an utterance being identified through a process of mutual adjustment. The idea is that the generation of candidate implicatures is an associative process (as opposed to a reasoning process that moves from premise to conclusion), but that the final selection of implicatures is dependent on identifying a development of the linguistically encoded meaning of the utterance that will provide proper inferential warrant for the implicatures. So while a linguistic form is uttered as a stimulus, rather than presented as an initial premise (a la Grice), it is still capable of development into the sort of thing that forms part of an interpretation, on the Relevance Theory model. In other words, linguistic forms and interpretations are made, to some degree, of the same stuff: both are semantically contentful objects.

Here, in more detail, is the process posited. The linguistic meaning of the utterance is decoded, resulting in the activation of concepts encoded by the utterance. This in turn activates the most accessible encyclopaedic information associated with those concepts. The Communicative Principle of Relevance (Sperber and Wilson, 1986/1995: 266-272) entitles the hearer to assume that these assumptions are what the speaker intended to communicate, as long as they justify the effort expended in accessing them. These activated assumptions, however, do not yet, according to the theory, have the status of implicatures. This is because the process by which they have been identified is not a procedure that relates a premise to a conclusion: it is simply a case of association triggered by a perceived ostensive stimulus. In order to elevate these assumptions to the status of implicatures, a process of backwards inference is required, whereby the linguistically encoded meaning of the utterance is inferentially adjusted, and perhaps augmented, until it implies those assumptions previously identified by association. This is how Wilson and Sperber put it:

the hearer's expectations of relevance warrant the assumption that the speaker's explicit meaning will contextually imply a range of specific consequences (made easily accessible, though not yet implied, by the linguistically encoded sentence meaning). Having identified these consequences, he may then, by a process of backwards inference, enrich his interpretation of the speaker's explicit meaning to a point where it does carry these implications (Wilson and Sperber, 2002). 
An example will probably help at this point. Mary's utterance in (35) does not commit her to the proposition that Sally is a supernatural being. Rather, it conveys a set of implicatures that includes those listed. If Peter were to find out later that Sally was in fact cruel and heartless, he might rebuke Mary by saying 'You said Sally was an angel'. In such a case, he would not be attributing the Sally the claim that Sally was a supernatural being. Hence, the property predicated of Sally by his use of 'angel' cannot be that which is encoded by that word. Rather, it is a distinct property that may differ in extension. This is the property that is constitutive of the concept that is represented by ANGEL*

(35)Peter: Will Sally look after the children if we get ill?

Mary: Sally is an angel

Explicature:

Implicatures:
Sally is an ANGEL*

Sally is exceptionally good and kind

Sally is watchful and will help when needed

Sally will look after the children if Peter and Mary get ill

(Wilson and Carston, 2007)

Applying the model outlined above to this example, the decoding of the linguistically encoded meaning of the utterance makes accessible assumptions about angels, such that they are typically good and kind. This in turn makes accessible, given the context of the utterance and the logical form of the sentence, assumptions about how Sally will behave should Peter and Mary become ill. Peter is justified in assuming that these accessible assumptions are what Mary intended to communicate by virtue of their accessibility and the fact that they provide the sort of effect he is seeking (i.e. a response to his question). So far, though, these assumptions do not have the status of implicatures as they are not implied: they are, in the parlance of the Wilson \& Sperber quote above, mere 'consequences' of the utterance. The final step, then, is to enrich and adjust the linguistically encoded meaning of the utterance until it does imply those consequences, thereby elevating the consequences to the status of implicatures. ${ }^{3}$

The difference between a rational reconstruction of the derivation of the implicature and the online identification of both explicature and implicature is partly one of sequencing: in a rational

\footnotetext{
${ }^{3}$ The claim that the assumption that provides warrant for the implicatures in a case such as (35) is a development of the linguistically encoded meaning of the utterance is open to challenge. Notice that it is by virtue of the theorist's choice of representation that 'Sally is an ANGEL' appears to be a development of the linguistically encoded meaning of 'Sally is an angel': if 'XYZ' is used instead of 'ANGEL' to represent the concept conveyed by the use of 'angel', then the putative explicit content looks far less like a development of the linguistically encoded meaning of the utterance. The properties denoted by ANGEL and ANGEL* are distinct, and the forms used to denote them are arbitrary.
} 
reconstruction, the explicature is treated as given, while in the model of online utterance interpretation, the proposition that implies the implicatures, and thereby confers that status upon them, is not a given starting-point, but arrived at through a process of backwards inference. This backwards inference takes into consideration the consequences of attending to the stimulus constituted by the production of a linguistic form in an ostensive act, and seeks, in an enrichment of the linguistically encoded meaning of the utterance, a reason for treating these as intended by the speaker.

My case against the view that explicit utterance content is a level of representation in utterance processing rests on the claim that this last step is redundant: nothing is gained through the process of backwards inference. On the model just outlined, the consequences of the utterance can be identified without engaging in reasoning from the initial premise. Consequently, derivation of the explicature must be motivated by some concern other than its implicative role. The claim is that deriving the explicature provides a warrant for the implicatures that they would otherwise lack (or, perhaps, that it explicitly represents a warrant that would otherwise remain latent). But, if the model is to work, then the process of consequence identification that delivers up the assumptions for which the explicature is to provide warrant must be reliable enough such that, when it functions normally, those assumptions are the ones intended by the speaker. If it were not, then there would be no hope of identifying either the explicit or the implicit communicated content of the utterance. But if the consequence-identification process (i.e. that part of the process triggered by the decoding of the linguistic form of the utterance) is reliable to this degree, then it is hard to see what additional benefit is achieved by seeking warrant through the identification of an explicature.

The warrant-seeking move would be justified if the explicature provided the hearer with cognitive effects additional to those constituted by the consequences of interpreting the utterances (i.e. by its nascent implicatures): this would potentially increase the relevance of the utterance. However, it has been argued convincingly by Allot and Textor (2012) that the conceptual content conveyed by communicated concepts constructed on-line as part of the Relevance Theory interpretation process amounts to no more than the information it activates in relation to a particular goal. This is precisely the information that, on the model just outlined, is made accessible by the decoding of the linguistic meaning and the consequent activation of accessible encyclopaedic information. If this is correct, then not only is it hard to see what benefit would be achieved by entertaining a representation of the explicit content of the utterance, but it is hard even to articulate just what would count as representing the explicit content of an utterance in terms that did not amount to grasping the overall import of the utterance. 
One objection to my argument that might be made is that, unless he identifies a content that gives inferential warrant for the consequences of the utterance, the hearer has no reason to accept these as intended by the speaker. This is the sort of position maintained by Allot (2007) in objection to purely associationist accounts of utterance interpretation, such as Recanati's $(2002,2004)$ primary pragmatic processes. Allot argues that, because such models are not warrant preserving, they do not offer an account of the rationality of utterance interpretation. However, one can respond by saying that if the activation procedures that are triggered by linguistic decoding (and thereby lead to the identification of relevant assumptions) are working normally, then the hearer has just as much reason to accept those assumptions as part of the speaker's intended meaning (i.e. as implicatures) as he has to form beliefs on the basis of perceptual input. In other words, the hearer doesn't need to seek warrant for the consequences of an utterance, but can rationally treat these as implicatures (i.e. intentionally communicated assumptions) on the basis that the procedure that delivered them is working normally, just as he can rationally form the belief that the cat is on the mat on the basis of the appropriate retinal stimulation. ${ }^{4}$

Recanati's $(2002,2004)$ model of pragmatic processes also assumes a notion of explicit utterance content. However, his distinction between primary and secondary pragmatic processes is also best reanalysed in terms of a distinction between material and behavioural content, or so I will argue. Recanati claims that there are two pragmatic systems: primary pragmatic processes that deliver up the explicit content of the utterance and secondary processes that derive implicatures, employing the output of primary processes as input. Primary pragmatic processes are viewed as sub-personal and not available to introspection. This is in contrast to secondary pragmatic processes which are open to introspection. Hence, for Recanati, it is the reflective availability of the reasons for an interpretation of an utterance that determines whether a pragmatically derived aspect of speaker meaning is part of what is said or what is implicated.

This 'availability principle' has received considerable criticism (e.g. Bach, 2001; Carston, 2002: 166$170)$ as a means of distinguishing explicit utterance content from implicatures. I will not go over this

\footnotetext{
${ }^{4} \mathrm{An}$ anonymous reviewer raises the concern that the possibility of utterance interpretation without identifying the explicature is compatible with Relevance Theory: once the effects required to justify the processing effort are met, the interpretation procedure should stop, regardless of whether an explicature has been identified at this point (along lines suggested by Korta and Perry, 2006). As far as I know, such a position has never been adopted by a prominent Relevance Theorist, and Allot's arguments would suggest that such a process would be rejected as not properly inferential, the implicatures being unwarranted. Furthermore, even if explicatureless interpretation were accepted as a possibility by Relevance Theorists, I would still push for the stronger claim that the identification of explicit utterance content ought not to be a goal of a model of basic, unreflective utterance interpretation. My claim in this paper is that we have no grounds for positing such a level of mental representation.
} 
criticism here. Rather, I want to suggest that what underlies the reflective distinction that Recanati seeks to capture is the distinction between materially and behaviourally conveyed utterance content. According to Recanati (2002: 114), implicatures are deviations from what Millikan (1984: 69) calls 'the normal language flow', which involves unreflective processes of comprehension. In communicating an implicature, according to this view, the speaker deliberately and overtly behaves in a manner that disrupts the normal language flow and invites an inference that seeks to explain her reasons for doing so, thereby communicating her intentions. This is clearly a case of behavioural implicature. However, it doesn't follow that the processes underlying the normal language flow are aimed at developing the linguistically encoded meaning into a representation of the utterance's explicit content: such an assumption needs to be justified. One way justification might be given is to claim that the explicit content of the utterance is required as an input into implicature derivation. Indeed, Recanati's model does treat the explicit content of the utterance as the basis for the derivation of implicatures, but consideration of the Relevance Theory model shows that what the explicit content of the utterance would provide warrant for (if warrant were needed, which, I have claimed, it is not) are material implicatures. These, however, are not disruptions in the normal language flow. What is needed in interpreting behavioural implicatures, by contrast, is a representation of the utterance qua action. This can be achieved by re-tokenining what is said by the utterance (respecting contextual parameters in relation to indexical constituents) and pairing this with the interpretation that its initial tokening resulted in. There is no need to posit a representation of explicit utterance content. ${ }^{5}$ Thus it is possible to conceive of a system in which primary processes deliver up interpretations, and secondary processes deal with disruptions in the normal language flow by inferring the intentions that underlie that disruption. On this view, primary processes are concerned with what, in a rational reconstruction, would be classified as the material implicatures of the utterance, while secondary processes are concerned with behavioural implicatures.

Models of utterance interpretation thus do not need to posit the representation of the explicit content of the utterance as a processing step. This should be welcome news, given the lack of agreement between theorists on whether classic cases are part of the explicit or implicit content of the utterance. For example, Recanati (2004: 44-46) sees the implicatures in Grice's out-of-petrol case as elements of the explicit content of the utterance (his version of what is said), treating 'garage' in much the same way as 'angel' is treated in (35), i.e. having its lexical meaning adjusted to

\footnotetext{
${ }^{5}$ In a discussion of irony in Jary (2013), I suggest that a metarepresentation of the explicit content of the utterance is required in the derivation of behavioural implicatures. This needs to be rethought. As has just been noted, the representation of the utterance qua utterance required by behavioural implicatures, such as those conveyed by ironic utterances, can be conceived of as a pairing of a token of what is said by an utterance with that utterance's interpretation.
} 
GARAGE* (where GARAGE* = garage that is open and has petrol to sell). Indeed, although a range of tests have been proposed for identifying the explicit content of the utterance, but none has met with universal acceptance: Carston (2009: 54) concedes that, after twenty years of effort, "it cannot be claimed that we have yet found a foolproof criterion that can be applied satisfactorily across all cases".

\section{Explicit utterance content and assertion}

We have, then, a level of meaning postulated by theorists which, I have argued, we have no need to assume is entertained by individuals interpreting an utterance and for which reliable diagnostics have not been identified. What grounds remain for positing explicit utterance content?

In order to consider this question, we need to return to Grice's distinction between what is said and what is implicated. Grice intended this distinction to reflect the distinction between what is asserted by a speaker and what is otherwise conveyed by her utterance, but which is nonetheless part of what she means. It was soon pointed out, though, that elements of a speaker's meaning that Grice wanted to call implicatures (by virtue of not being part of the conventional significance of the sentence uttered) contribute to the truth-conditional content of the utterance, i.e. that which the speaker would be taken to have asserted. This led theorists to posit a hybrid level of speaker meaning, part encoded/conventional and part inferential in its derivation.

That such a level is needed might be argued for on the grounds that there is a very strong intuitive difference between what is asserted and what is otherwise communicated by an utterance, and that what is asserted has been shown to be underdetermined by what, in Grice's austere conception, is said. This difference is often illustrated by citing Grice's (already discussed) philosophy job example, in which an utterance of (29) implicates that $\mathrm{MrX}$ is no good a philosophy (Grice, 1989). This example certainly brings out sharply the difference between what is asserted (29) and what is otherwise conveyed (30).

(29)Mr X's command of English is excellent, and his attendance at tutorials has been regular. (30)Mr. X is no good at philosophy.

But, as we have seen, this difference can be accounted for in terms of the distinction between behavioural and material implicatures outlined in section 4.2. If behavioural implicatures are set to one side, and we consider only material implicatures, then it becomes harder to draw the line between the explicit and the implicit content of an utterance. Indeed, if Allot and Textor (2012) are right about the content of ad hoc concepts being no more than the information that they convey, and if, as Relevance Theorists argue, ad hoc concepts contribute to the explicit content of the 
utterance, then no line can be drawn, for material implicatures such as those in (35) just are the explicit content of the utterance.

Bach (1994) differs from the theorists discussed in section 4 in that his notion of impliciture is not argued for on processing grounds. Rather, he claims that this notion is needed in order to account for part of what the speaker means that is neither said nor implicated. What is said, for Bach, is determined solely by the linguistic meaning of the utterance, so that speakers can say things that they do not mean (as in cases of slips of the tongue and non-literal utterances). What is implicated is implied by the saying of what is said. How does the impliciture arise? Bach says that it is implicit in what is said. But given that it is a pragmatic development of what is said, it must also be derived from the saying of what is said. This, however, bases its taxonomic separation from implicature purely on the semantic features it shares with what is said. This is a comparatively weak basis for a separation, given that what is implicated and what is said are distinguished, in both Grice's and Bach's frameworks, on far more robust grounds: the distinction between decoding/convention and reasoning. Furthermore, that an impliciture is an expansion of what is said appears to play no explanatory role: there is no claim that hearer arrives at it by seeking to find warrant for the implicatures, as on the Relevance Theory story. So, while not quite redundant in Bach's framework, the distinction does little more than serve to alert us that some aspects of pragmatically derived meaning can be expressed using expansions of the linguistic form of the utterance.

The reason, I think, that the notion of explicit utterance content holds such sway, even among those like Bach for whom it does little explanatory work, is that it seeks to capture the aspect of speaker meaning that determines the truth conditions of the utterance. Given the importance of truth judgments in human affairs, and the sense we have that objective decisions can be made concerning the truth or falsity of many utterances of declarative sentences, it is natural to seek criteria for identifying that aspect of the speaker's meaning that determine whether what she says is true or false. However, further reflection reveals that what falls under a truth judgement depends very much on local conditions. B's utterance in (36) is felt to be true if she has had lunch on the day of the utterance, false otherwise, even though she is bound to have eaten at some time in the past. Hence the truth conditions of her utterance are expressed explicitly by (37).

(36)A: Would you like to join us for lunch?

B: I've eaten, thanks.

(37)B has eaten lunch on the day of her utterance (36) 
In such informal interactions, B would not get much of a sympathy defending her deception by saying that what she had said was literally true. In a more adversarial setting, by contrast, literal meaning can be called upon in defence. When originally uttered, President Clinton's claim in (38) was enriched by many hearers so that its truth conditions were taken to be (39). Under later crossexamination, however, he was able to argue that what he had claimed was that at the time of utterance there was no improper relationship, i.e. the literal meaning of the sentence uttered. ${ }^{6}$ What counts as the truth-conditional content of the utterance thus depends on the nature of the interaction. When objective grounds are needed, as in a court case, the tendency is to resort to the literal meaning of the utterance (see Hansen, 2008, for discussion and authentic examples from court proceedings).

(38)There is no improper relationship.

(39)There is not and never has been an improper relationship.

Thus the fact that we can judge utterances true or false need not entail that they have objective truth conditions. Rather, those aspects of the utterance that fall under a truth judgement differ according to the type of interaction of which the utterance forms part. What count as the truth conditions of an utterance is not to be determined by semantic and pragmatic theorising, but something to be agreed, tacitly or otherwise, by those engaged in truth judgements. In debates about the truth conditions of the utterance, the focus will be on its linguistic form, for this is the aspect of the utterance that can most readily be re-tokened. This is why, in disputed cases, what the speaker said plays such a large role in determining what she thereby committed herself too.

\section{A case for semantic minimalism?}

The case for explicit utterance content has often been presented as being in opposition to those who champion the minimal proposition expressed by an utterance, which is essentially Grice's notion of what is said (Borg, 2004; Cappelen and Lepore, 2005). I have made a case against the notion of explicit utterance content, and I have noted that it is the literal meaning of the utterance that will often be taken to be decisive in high-stakes questions concerning the truth of an utterance. Have I therefore made a case for semantic minimalism?

The case against minimalism made by Relevance Theorists is that the minimal proposition expressed by the utterance has no role to play in a theory of utterance interpretation (Carston, 2008a, b). My claim has been that neither does the notion of explicit utterance content (i.e. the Relevance Theory

\footnotetext{
${ }^{6}$ See Saul (2012) for extensive discussion of this case.
} 
notion of explicature), the reason being that utterance interpretation can be modelled without it. Defenders of minimalism differ on the role they assign to this level of meaning. For Cappelen and Lepore, the minimal proposition is a starting point for working out what the speaker could have meant when one has limited access to the original situation of utterance. But this is a reflective process, distinct from the process of comprehending an utterance when one is party to a linguistic interaction: they posit no role for the minimal proposition in utterance comprehension. Borg, by contrast, wants the minimal proposition to be the output of online linguistic comprehension (i.e. the output of a semantics module), but offers no account of how this output plays a role in utterance interpretation, i.e. how it interacts with pragmatics. So, I think the case made by Relevance Theorists against minimalism holds, and the case against their alternative to the minimal proposition (i.e. against explicature) isn't a case for minimalism. It is quite possible that the input to utterance comprehension is very different from what we rely on when we reflect on language use. In such reflections, the minimal proposition has a role to play. In online comprehension, however, it is plausible that encoded features of utterances to which we have little or no intuitive access are key. ${ }^{7}$

In a reflective process such as a rational reconstruction, by contrast, the minimal proposition does have a role to play: it is the basis for the calculation of implicatures. This is so even in the sort of cases discussed by Relevance Theorists in relation to lexical pragmatics. Returning to (35), the rational reconstruction need not take as its initial premise the alleged explicature. Rather as in (35)' the implicatures of the utterance can be derived via forward inference what is said (cf. Wilson and Carston, 2007: 248). Of course, further justification is needed to show that the implicatures are what the speaker meant, ${ }^{8}$ but the fact that a reconstruction can be made from what is said to the implicatures of the utterance shows that it is a reasonable interpretation. ${ }^{9}$

(35)Peter: Will Sally look after the children if we get ill?

Mary: Sally is an angel

Explicature: $\quad$ Sally is an ANGEL*

Implicatures: Sally is exceptionally good and kind Sally is watchful and will help when needed

\footnotetext{
${ }^{7}$ According to the Chomsky-inspired view defended by Pietroski (2005), for example, the information conveyed by the linguistic form of an utterance is far removed from anything propositional.

${ }^{8}$ In Jary (2013), I argue that the role of speaker intentions (and other mental states) is distinct in material and behavioural implicatures: in the former they are required to justify the employment of certain auxiliary premises required to get from what is said to what is implicated; in the latter they are required to serve as premises.

${ }^{9}$ So the definition of a material implicature in Jary (2013) needs to be refined as an implicature that is derivable from what is said, rather than from the explicit content of the utterance.
} 
(35)' Sally is an angel.

Sally will look after the children if Peter and Mary get ill

Angels are good and kind.

Sally is good and kind.

Someone who is good and kind will look after the children if they get ill.

Sally will look after the children if they get ill.

\section{Conclusion}

The fact that the linguistic meaning of an utterance greatly underdetermines the content of the utterance is an important insight, and the work done by theorists detailing the many forms which this underdetermination takes is extremely valuable. However, it is rash to conclude from this work that interpreting an utterance involves in some way augmenting and adjusting the linguistically encoded content of the utterance. Consider a parallel with the referring use of definite descriptions. We might use any one of a number of descriptions to refer to an individual, but we do not feel compelled to say that interpreting a description requires enriching it into a determinate description of the individual referred to. Rather, we assume that the description 'the man' or 'the man with the large hat' is sufficient for the hearer to identify the intended individual in that situation of utterance. Likewise, we should view the utterance of a declarative sentence as a means of identifying a state of affairs, with tokens of different types of forms being used to identify the same state of affairs on different occasions, and different states of affairs being identified by tokens of the same type of form on different occasions. Once the intended state of affairs has been identified by the hearer, he will have access to a rich representation of that state of affairs to draw on in his interpretation of the utterance, and this will support further assertions that will count as manifestations of that interpretation. But just as we would not want to say that the identification of the individual referred to by the use of a definite description amounts to an enrichment of that description, nor should we jump to the conclusion that the identification of the state of affairs picked out by the utterance of a declarative sentence amounts to an adjustment and augmentation of the encoded meaning of that sentence. Indeed, it would seem that we have little reason to make this assumption.

\section{Acknowledgements}

I am grateful to the following for comments, encouragement and support in writing this paper: Nick Allott, Robyn Carston, Mikhail Kissine, Rob Stainton and Agustin Vicente.

\section{Funding}


This work was supported by Research Project: Lexical Meaning and Concepts, FFI2014-52196-P, awarded by the Spanish Ministry of Economy and Competitiveness.

\section{References}

Allott, Nicholas: 2007. Pragmatics and rationality, Linguistics Dept. University College London, London.

Allott, Nicholas; Textor, Mark: 2012. Lexical pragmatic adjustment and the nature of ad hoc concepts, International Review of Pragmatics, pp. 185-208.

Austin, John Langshaw: 1962/1975. How to do things with words, 2nd ed. Harvard University Press, Cambridge MA.

Bach, Kent: 1994. Conversational impliciture. Mind and Language 9, 124-162.

Bach, Kent: 2001. You don't say? Synthese 128, 15-44.

Borg, Emma: 2004. Minimal semantics. OUP, Oxford.

Brandom, Robert: 1994. Making it explicit: Reasoning, representing, and discursive commitment.

Harvard University Press, Cambridge, MA.

Cappelen, Herman; Lepore, Ernie: 2005. Insensitive semantics: A defense of semantic minimalism and speech act pluralism. Blackwell, Oxford.

Carston, Robyn: 2002. Thoughts and utterances: The pragmatics of explicit communication.

Blackwell, Oxford.

Carston, Robyn: 2008a. Linguistic communication and the semantics/pragmatics distinction.

Synthese 165, 321-345.

Carston, Robyn: 2008b. Minimal semantics - by Emma Borg. Mind \& Language 23, 359-367.

Carston, Robyn: 2008c. Relevance theory and the saying/implicating distinction, The Handbook of Pragmatics. Blackwell Publishing Ltd, pp. 633-656.

Carston, Robyn: 2009. The explicit/implicit distinction in pragmatics and the limits of explicit communication. International Review of Pragmatics 1, 35-62.

Cohen, L. Jonathan: 1971. Some remarks on Grice's views about the logical particles of natural language, in: Bar-Hillel, Y. (Ed.), Pragmatics of Natural Language. Reidel, Dordecht, pp. 50-68. Green, Mitchell S: 1998. Direct reference and implicature. Philosophical Studies 91, 61-90.

Grice, Paul: 1989. Studies in the way of words. University Press, Harvard.

Hansen, Maj-Britt Mosegaard: 2008. On the availability of 'literal' meaning: Evidence from courtroom interaction. Journal of Pragmatics 40, 1392-1410.

Hinzen, Wolfram: 2015. Nothing is hidden: Contextualism and the grammar-meaning interface. Mind \& Language 30, 259-291.

Jary, Mark: 2013. Two types of implicature: Material and behavioural. Mind \& Language 28, 638-660.

Korta, Kepa; Perry, John: 2006. Three demonstrations and a funeral. Mind and Language 21, 137-

240.

Millikan, Ruth: 1984. Language, thought and other biological categories. MIT Press, Cambridge, MA.

Pietroski, Paul M: 2005. Meaning before truth, in: Preyer, G., Peters, G. (Eds.), Contextualism in

Philosophy. OUP, Oxford.

Recanati, Francois: 1989. The pragmatics of what is said. Mind \& Language 4, 295-329.

Recanati, Francois: 2002. Does linguistic communication rest on inference? Mind and Language 17, 102-126.

Recanati, Francois: 2004. Literal meaning. CUP, Cambridge.

Saul, Jennifer M.: 2012. Lying, misleading, and what is said: An exploration in philosophy of language and in ethics. OUP, Oxford.

Sperber, Dan ; Wilson, Deirdre: 1986/1995. Relevance: Communication and cognition, 2nd ed.

Blackwell, Oxford. 
Sperber, Dan; Wilson, Deirdre: 1998. The mapping between the mental and the public lexicon, in: Carruthers, P., Boucher, J. (Eds.), Thought and language. CUP, Cambridge, pp. 184-200.

Wilson, D.; Carston, Robyn: 2007. A unitary approach to lexical pragmatics: Relevance, inference and ad hoc concepts, in: Burton-Roberts, N. (Ed.), Pragmatics. Palgrave, London, pp. 230-259.

Wilson, Deirdre: 2003. Relevance Theory and lexical pragmatics. Italian Journal of Linguistics/Rivista di Linguistica 15, 273-291.

Wilson, Deirdre; Sperber, Dan: 2002. Truthfulness and relevance. Mind 111, 583-632.

Wilson, Deirdre; Sperber, Dan: 2012. Meaning and relevance. CUP, Cambridge. 